\title{
An Empirical Study on Educational Investment of Different Hierarchical Structures and Economic Growth in China
}

\author{
Yiping Hong \\ School of Economics and Management, Haidian Campus, Hainan University, Haikou City, Hainan Province \\ 570228, China \\ 13016209883@163.com
}

Keywords: Education investment, educational investment structure, economic growth.

\begin{abstract}
At present, the relationship between education and economy has been widely concerned by scholars at home and abroad. On the basis of reading literature, this paper studies the relationship between economic growth and education input at different levels. This paper chooses panel data of 31 provinces in China from 2005 to 2014, and examines the impact of higher education input, secondary education investment and primary education investment on GDP growth through empirical analysis. The results show that, from a national perspective, secondary education has a positive effect on GDP growth rate, primary education and higher education have negative effects on GDP growth rate. This may be due to the hysteresis of education input, and it may also indicate that Chinese current education investment structure needs to be adjusted.
\end{abstract}

\section{Introduction}

The role of education for economic growth has been widespread concern, domestic and foreign scholars have been committed to this point. At present, the study on the impact of education on economic growth is mainly focused on two aspects: First, the study of education as a whole, the second is focus on higher education. Romer (1986) and Lucas (1988) proposed an endogenous economic growth theory that illustrates the important role of human capital in economic growth. Barro (1991) argued that human capital has a significant positive impact on economic growth. Schultz \& Peters \& Hedley (1995) argued that higher education promotes economic development by improving human capital. Sarah Batterbury \& Steve Hill (2005) systematically assessed the impact of higher education on regional development. Jorgenson \& Fraumeni (1991) discussed the fact that education was seen as an investment in human capital during the postwar period and was the overwhelming majority of US economic growth. Ganegodage and Rambaldi (2011), based on the neoclassical growth theory and the endogenous economic growth theory, assessed the contribution of education investment in Sri Lanka to economic growth in 1959-2008, believing that investment in education was positively related to economic growth. Yusuf (2014) studied the impact of Nigeria's education investment on economic growth from 1975 to 2012 from the perspective of human capital investment and labor capital investment. Domestic scholars mainly focus on three major areas: First, the impact of education investment and investment structure on economic growth. Junjie Ji, Xiuyang Zhou (2011), based on the empirical study about the relationship between educational input and economic growth in 1992-2008, the marginal contribution rate of education funding from different sources to economic growth is different. Xinrong Liu and Lingfang Zhan (2013) used the provincial panel data of China to study the rationality of educational investment structure in China by introducing the structural variables of educational investment and examined the impact of educational investment and its structure on economic growth, the results showed that from the national perspective , the effect of educational input on economic growth is positive, the coefficient is 0.0102 , the structure of educational investment has an inverted U-shaped effect on economic growth and the current educational 
investment structure is reasonable. However, Xiangrong Wu (2007), Ming Zheng and Huaizhen Zhu (2007) believed that since the university enrollment, more than half of colleges and universities to a certain extent hindered the local economic development, there was excessive education in China. Second, the impact of higher education investment and hierarchical structure on economic growth. Shukuan Zhao, Haiqing Yu , Zhanli Liu (2011), considering the manpower investment and the financial investment in higher education as input indicators, researching the relationship between higher education investment and economic growth, the result is that there is a long-term dynamic equilibrium relationship between the higher education funding, manpower input and economic growth, and higher education investment is the main power to promote the economic growth in China, a 1 percentage point increase in higher education funding translates to 0.251 percentage points of economic growth. Wenbin Zhang (2012) used the Cobb-Douglas production function to calculate the contribution rate of higher education to economic growth. Yuxuan Yang (2012) studied the adaptation and matching of higher education structure adjustment and economic growth, concluded that the hierarchical structure of higher education in China had undergone an adjustment process which was never adapted to economic growth and adjusted to gradual adaptation,and there was a nonlinear correlation between the two variables, the fitting was three curve relation. Third, the impact of higher education on regional development. Yingchun Zhu and Dapeng Wang (2010) applied the production function method, finding that the average contribution rate of Chinese higher education to economic growth in 1996-2006 was only $1.267 \%$, and the regional differences were large, showing a gradual decline distribution from east to central and western regions. Zichen Wang (2015) introduced the coordination degree model to measure the degree of coordination between higher education and regional economic growth. The results showed that the distribution of higher education resources was uneven. In addition, a few scholars have studied the relationship between educational structure (primary, secondary and higher) and economic growth. Xuehui An (2002) analysed that 1981 to 1955, the contribution rates of Chinese primary, secondary and higher education human capital contribution to economic growth were $16 \%$, $10 \%, 12 \%$. But Xuehui An only measured contribution rate of economic growth from the perspective of human capital, she did not take into account of the relationship between different structural levels of education investment and economic growth. Chuhui Liao (2004) pointed out that the role of education investment in economic growth depended not only on the total amount of education investment, but also on the structure of education investment (basic education, secondary education and higher education), but he did not go into depth studies.

All above, it is not difficult to see that the existing research is more focused on the impact of educational input and input structure on economic growth, the impact of higher education input and hierarchical structure on economic growth, the impact of higher education on regional development, and there is little research on the relationship between educational input of different hierarchical structures and economic growth.

\section{Method}

\subsection{Establishment of multiple regression model}

This paper intends to use multiple linear regression model to analyze the impact of educational input on economic growth in various hierarchical structures. The general form of the multiple linear regression model is as follows:

$$
Y_{i}=\beta_{0}+\beta_{1} X_{1 i}+\beta_{2} X_{2 i}+\beta_{3} X_{3 i}+\varepsilon_{\mathrm{i}}(i=1,2, \ldots, n)
$$

\subsection{Index selection}

\subsubsection{Educational hierarchy structures and capital investment}

As a representative of the various levels of education investment in the sample data, at present, we usually select primary education, secondary education and higher education as the hierarchical indicators of education. In order to reflect the capital investment of all the educational hierarchies in 
China, this paper chooses the expenditure of education in different levels (primary education, secondary education, higher education) in 31 provinces in China from 2005 to 2014, as a common reflection of the main indicators of changes in educational input at all hierarchical levels.

\subsubsection{Economic growth}

There are many indicators of economic growth. This paper chooses the GDP growth rate of 31 provinces in China from 2005 to 2014 as the measure of economic growth.

\subsection{Data}

\subsubsection{Data sources and descriptive statistics}

This paper uses data from 31 provinces in China between 2005 and 2014. Among them, The GDP data are from the National Bureau of statistics, and the data on education input comes from the annual statistics yearbook of educational funds in China. Table 1 is the descriptive statistics results of each variable.

Table 1 Descriptive statistics of variables

\begin{tabular}{|c|c|c|c|c|c|}
\hline & Obs & Mean & Std.Dev & Max & Min \\
\hline 0 & 310 & $15.79 \%$ & 0.0595 & $32.27 \%$ & $0.59 \%$ \\
\hline $\begin{array}{l}\text { Expenditure on education in } \\
\qquad(100 \text { millior }\end{array}$ & 310 & 170.907 & 51.153 & 1.1430 & 4.2231 \\
\hline $\begin{array}{l}\text { Secondary school education expenditure (100 million } \\
\text { yuan) }\end{array}$ & 310 & 173.539 & 133.7568 & 81.723 & 7.2739 \\
\hline Primary education expenditure (100 million yuan) & 310 & 3.57 & 23.44 & 732.1937 & 10.005 \\
\hline
\end{tabular}

\subsubsection{Data processing}

In order to eliminate the volatility of variables and the resulting heteroscedasticity, and to better reveal the relationships among variables, we take logarithms of the explanatory variables. Therefore, our model is set as:

$$
Y_{i}=\beta_{0}+\beta_{1} \operatorname{Ln}\left(X_{1 i}\right)+\beta_{2} \operatorname{Ln}\left(X_{2 i}\right)+\beta_{3} \operatorname{Ln}\left(X_{3 i}\right)+\varepsilon_{i}(i=1,2, \ldots, n)
$$

Where

$Y$ : GDP growth rate

$X_{1}$. Higher education expenditure

$X_{2}$ : Secondary school education expenditure

$X_{3}$ : Primary education expenditure 


\section{Result}

\subsection{Multiple linear regression}

Multiple regression results are shown in Table 2:

Table 2 Multiple regression results

\begin{tabular}{ccccc}
\hline Variable & Coefficient & Std. Error & t-Statistic & Prob. \\
\hline C & 0.265516 & 0.018217 & 14.57486 & 0.0000 \\
Ln(X1) & -0.013691 & 0.007701 & -1.777710 & 0.0764 \\
Ln(X2) & 0.067739 & 0.026090 & 2.596374 & 0.0099 \\
Ln(X3) & -0.077993 & 0.021599 & -3.610925 & 0.0004 \\
R-squared & 0.128332 & & & \\
Adjusted R-squared & 0.119786 & & & \\
F-statistic & 15.01702 & & & \\
Probability(F-statistic) & 0.000000 & & & \\
\hline
\end{tabular}

So the multiple linear regression equation is as follows:

$$
Y=0.265516-0.013691 \operatorname{Ln}\left(X_{1}\right)+0.067739 \operatorname{Ln}\left(X_{2}\right)-0.077993 \operatorname{Ln}\left(X_{3}\right)
$$

According to the results of the analysis, the $\mathrm{P}$ value of the $\mathrm{F}$ test is less than 0.1 , so the whole regression equation is significant. According to the $t$ test, it is found that the $\mathrm{P}$ value of all the coefficients is less than 0.1 , indicating that the coefficient is significant. $(a=0.1)$

\subsection{Unit root test}

Table 3 Unit root test results

\begin{tabular}{cccc}
\hline & Variable & t-Statistic & Prob. \\
\hline & $\mathrm{Y}$ & -4.568513 & 0.0014 \\
Augmented Dickey-Fuller test statistic & $\operatorname{Ln}(\mathrm{X} 1)$ & -10.36911 & 0.0000 \\
& $\operatorname{Ln}(\mathrm{X} 2)$ & -10.82081 & 0.0000 \\
& $\operatorname{Ln}(\mathrm{X} 3)$ & -9.223691 & 0.0000 \\
\hline
\end{tabular}

According to the unit root test results, it can be found that the probability $\mathrm{P}$ of the ADF value of $\mathrm{Y}$ is 0.0014 and the probability P of the ADF values of Ln (X1), Ln (X2) and Ln (X3) are 0.0000, so we can refuse the original hypothesis which have a unit root, thus the sequence is stable. Therefore, it is possible to directly use Y, Ln (X1), Ln (X2), and Ln (X3), and the pseudoregression phenomenon does not occur.

\subsection{Heteroscedasticity test}

Table 4 Heteroscedasticity Test: Breusch-Pagan-Godfrey

\begin{tabular}{cccc}
\hline F-statistic & 2.502022 & Prob. F(3,306) & 0.0594 \\
\hline Obs*R-squared & 7.422123 & Prob. Chi-Square(3) & 0.0596 \\
\hline Scaled explained SS & 5.407256 & Prob. Chi-Square(3) & 0.1443 \\
\hline
\end{tabular}

According to the table 4, we found that Prob. Chi-Square $(3)=0.0596$, indicating that the equation greatly reduces the heteroscedasticity.

\section{Conclusion}

We can find that secondary education has a positive effect on GDP growth, and primary and higher education have a negative effect on GDP growth. 
Firstly, from the hysteresis of the investment in education to GDP growth, the model used in this paper only discuss the impact of current investment in education on the current economic growth, does not consider the hysteresis. In the short term, education investment can not immediately have a positive impact on economic growth, which also lead to a negative coefficient of primary education and higher education in the model.

Secondly, from the overall structure of education, the model reflects the current educational structure in China needs to be adjusted. Primary education and higher education resources are over invested, we should reduce the input; and secondary education resources need to increase investment in order to promote GDP growth.

Thirdly, in terms of crowding out effect, the negative impact of education input on higher education and primary education may be due to excessive investment, which takes up other resources that contribute to economic growth, resulting the growth of GDP is negative as a whole. The positive effect of secondary education input may be due to the fact that secondary education inputs have led to the development of other industries, thus contributing to GDP growth in general.

\section{References}

[1] Romer P M. Increasing returns and long-run growth [J]. Journal of political economy, 1986, 94(5): 1002-1037.

[2] Lucas R E. On the mechanics of economic development [J]. Journal of monetary economics, 1988, 22(1): 3-42.

[3] Barro R J. Economic growth in a cross section of countries [J]. The quarterly journal of economics, 1991, 106(2): 407-443.

[4] Schultz T P, Peters G H, Hedley D D. Human capital and economic development.[C]// Conference, August 22-29, 1994, Harare, Zimbabwe. International Association of Agricultural Economists, 1995.

[5] Batterbury S, Hill S. Assessing the Impact of Higher Education on Regional Development [J]. Higher Education Management \& Policy, 2005, 16(3):22-22.

[6] Jorgenson D W, Fraumeni B M. Investment in Education and U.S. Economic Growth. [J]. Scandinavian Journal of Economics, 1991, 10(94): 51-70.

[7] Ganegodage K R, Rambaldi A N. The impact of education investment on Sri Lankan economic growth [J]. Economics of Education Review, 2011, 30(6):1491-1502.

[8] Yusuf S A. The Analysis of Impact of Investment in Education on Economic Growth in Nigeria: Veracity of Association of Staff Union of University of Nigeria's agitation [J]. Sulaim on Yusuf, 2014, 12(s 11-12):57-66.

[9] Ji Junjie, Zhou Xiuyang. An Empirical Study on the Relationship between Education Input and Economic Growth in China: Also on the Necessity of Fiscal Educational Funds Growth [J]. Modern Education Management, 2011, (12): 26-29.

[10] Liu Xinrong, Zhan Ling Fang. The impact of educational investment and its structure on Chinese economic growth [J]. Education and economics, 2013, (03): 49-55.

[11] Wu Xiangrong. The phenomenon of excessive education in the expansion of education and its income effect: Empirical study based on the present situation in China [J]. Journal of Beijing Normal University (Social Science Edition), 2007, (03): 132-136.

[12] Zheng Ming, Zhu Huaizhen. Higher education and regional economic growth --An Empirical Study Based on Chinese Provincial Panel Data, [J]. Tsinghua University Education Research, 2007 (04): 76-81.

[13] Zhao Shukuan, Yu Haiqing, Liu Zhanli.Theoretical model and empirical study on the 
relationship between higher education investment and economic growth [J].Chinese Higher Education Research, 2011, (09): 11-15.

[14] Zhang Wenbin. Study on the relationship between higher education and regional economic growth [D]. Northeast Normal University, 2012.

[15] Yang Yuxuan. Study on the relationship between higher education hierarchical structure adjustment and economic growth [D]. Southwestern University of Finance and Economics, 2012.

[16] Zhu Yingchun, Wang Dapeng. Contribution of higher education to regional economic growth: An Empirical Study Based on Provincial Panel Data [J]. Soft Science, 2010, (02): 79-82+98.

[17] Wang Zichen. Study on the measurement of the relationship between higher education and Chinese economic growth [D]. University of Science and Technology of China, 2015.

[18] An Xuehui. Analysis of the contribution rate of three grade education to economic growth in China [J]. Journal of Tianjin Academy of Educational Science, 2002, (02): 26-31.

[19] Liao Chuhui. Dynamic analysis of regional imbalance in government expenditure [J]. Economic Research, 2004, (06): 41-49. 